\title{
Variances in the mRNA expression profile of TGF- $\beta 1-3$ isoforms and its TGF- $\beta$ RI-III receptors during cyclosporin a treatment of psoriatic patients
}

\author{
Anna Michalska-Bańkowskaㄹ, Dominika Wcisło-Dziadecka², Beniamin Grabarek², Ligia Brzezińska-Wcisło', \\ Urszula Mazurek ${ }^{3}$, Natalia Salwowska ${ }^{1}$, Mirosław Bańkowski ${ }^{4}$
}

${ }^{1}$ Chair and Department of Dermatology, School of Medicine, Medical University of Silesia, Katowice, Poland

${ }^{2}$ Department of Skin Structural Studies, Chair of Cosmetology, School of Pharmacy with Division of Laboratory Medicine in Sosnowiec, Medical University of Silesia in Katowice, Poland

${ }^{3}$ Chair and Department of Molecular Biology, School of Pharmacy with Division of Laboratory Medicine in Sosnowiec, Medical University of Silesia in Katowice, Poland

${ }^{4}$ Department of Neurology, District Health Care Centre, Czeladź, Poland

Adv Dermatol Allergol 2018; XXXV (5): 502-509

DOI: https://doi.org/10.5114/ada.2018.77242

\begin{abstract}
Introduction: Psoriasis is a chronic, immunologic, multi-factor inflammatory skin disease, strongly associated with a higher level of a number of cytokines, such as isoforms of transforming growth factor $\beta$ (TGF- $\beta 1-3)$ and its receptors (TGF- $\beta$ RI-III). One of the most popular and important drugs used to treat this disease is cyclosporin A (CsA). Aim: The aim of this study was to investigate the expression of genes encoding the transforming growth factor (TGF)- $\beta$ isoforms and receptors of the cytokine TGF- $\beta$ Rs in psoriatic patients during an 84-day long observation of the effects of cyclosporin A therapy. It made an attempt to determine the usefulness of testing mRNA expression of TGF- $\beta 1-3$ and its receptors TGF- $\beta R I-I I I$ as the supplementary molecular markers of lost sensitivity to the medicine. Material and methods: The study group consisted of 32 patients with psoriasis ( 20 men and 12 women) treated with cyclosporin A. The changes in expression patterns of TGF- $\beta 1-3$ and TGF- $\beta R$ I-III were performed by real-time quantitative reverse transcription PCR (RTqPCR).

Results: The expression of TGF- $\beta 1-3$ and TGF- $\beta R I-I / I$ were detected in the whole period of therapy with CSA. Changes in transcriptional activities of TGF- $\beta 1-3$ and TGF- $\beta R /-I I I$ during pharmacotherapy were observed. Differences in the expression of these genes were found before and after 42 and 84 days of using CsA.

Conclusions: The changes in expression profiles of TGF- $\beta 1-3$ and TGF- $\beta R$ I-III during CSA therapy can be a useful molecular marker of lost sensitivity to the medicine.
\end{abstract}

Key words: mRNA, transforming growth factor $\beta 1-3$, psoriasis, cyclosporin A.

\section{Introduction}

Psoriasis is a chronic, immunologic, multi-factor inflammatory skin disorder found globally in 1-3\% of the population [1-3]. There are two peaks of incidence in psoriasis: 20-30 years of age and 50-60 years of age. Miller et al. [4] confirm, based on a broad meta-analysis, that psoriasis is associated with cardiovascular diseases - ischemic heart disease, peripheral vessels disease and atherosclerosis, diabetes, arterial hypertension, dyslipidemia, and obesity [4-13]. Psoriatic patients show a higher risk of metabolic syndrome development, increasing with the disease severity [14-16]. Severe psoriasis is associ- ated with an increased cardiovascular mortality rate, the risk of cerebral stroke and heart attack is increasing [17].

Transforming growth factor $\beta$ (TGF- $\beta$ ) is a pleiotropic cytokine, with a dimeric polypeptide structure, built of 112 amino acids $[18,19]$. TGF- $\beta 1$ isoform is a cytokine circulating in the whole human body which affects a series of physiological and pathophysiological processes $[20,21]$. TGF- $\beta 1$ is mainly located in stratum corneum and stratum granulosum of the skin, TGF- $\beta 2$ is also in stratum spinosum and TGF- $\beta 3$ can be found in the basal layer and underneath [22]. TGF- $\beta 1$ may also play an important role in psoriasis pathogenesis, where the signalling involving cytokines is disturbed [18].

Address for correspondence: Dominika Wcisło-Dziadecka PhD, MD, Department of Skin Structural Studies, Chair of Cosmetology, School of Pharmacy with Division of Laboratory Medicine, Medical University of Silesia, 3 Kasztanowa St, 41-200 Sosnowiec, Poland, phone/fax: +48 3225 91 580/581/+48 32 256-11-82, e-mail: ddziadecka@interia.pl Received: 31.12.2017, accepted: 8.01.2018. 
Cyclosporin A (CsA) is a strong immunomodulatory and immunosuppressive medicine, which - through the inhibition of calcineurin phosphatase - prevents the transcription process of genes responsible for the synthesis of inflammatory cytokines necessary to activate T lymphocytes. The recommended average dose of CSA is $2.5-5 \mathrm{mg} / \mathrm{kg}$ body mass/day [23, 24]. Nevertheless, an initial dose should be $4-5 \mathrm{mg} / \mathrm{kg}$ of body mass, taken twice a day for 2-4 weeks, and then the dose is recommended to be gradually reduced [25].

\section{Aim}

The aim of this paper was to show which of TGF- $\beta$ isoforms and its receptors change their transcription activity in the peripheral blood in psoriatic patients during an 84-day long observation of the effects of CsA therapy. Moreover, an attempt was made to determine the usefulness of testing mRNA expression of TGF- $\beta 1-3$ and its receptors TGF- $\beta R$ I-III as supplementary molecular markers of lost sensitivity to the medicine.

\section{Material and methods}

\section{Whole blood}

The study group consisted of 32 patients with psoriasis (20 men and 12 women) who gave their informed consent to participate in the trial, aged 30 to 60 , treated with CsA due to psoriasis. The patients were taking CsA orally, at an average dose of $2.5-\mathrm{mg} / \mathrm{kg}$ of body mass in the morning and in the evening. Their whole blood was taken three times: on the day of therapy commencement (day 0 , on day 42 and day 84 of therapy).

\section{Total RNA extraction}

Total RNA was isolated from the whole blood with the use of FENOZOL (A\&A Biotechnology, Gdańsk, Poland) in two stages. The first stage commenced with an addition of $800 \mu \mathrm{l}$ of Fenozol to $500 \mu \mathrm{l}$ of the whole blood. It was then vortexed and incubated for $10 \mathrm{~min}$ at $50^{\circ} \mathrm{C}$. Upon another vortexing, $600 \mu \mathrm{l}$ of chloroform was added and then it was vortexed and centrifuged at $4{ }^{\circ} \mathrm{C}$ for $20 \mathrm{~min}$ at 13,000 rotations/min. The upper fraction containing RNA was transferred to a new test tube and $600 \mu \mathrm{l}$ of isopropanol was added. The next stage involved freezing at a temperature of $-20^{\circ} \mathrm{C}$ for the whole night, and it finished the first stage of RNA isolation. The second stage involved addition of $200 \mu$ l of D solution from $\beta$-mercaptoethanol, and $200 \mu$ lof isopropanol. The whole mixture was then frozen for 90 min at a temperature of $-20^{\circ} \mathrm{C}$. During the next stage, the samples were centrifuged at $4^{\circ} \mathrm{C}$ for $20 \mathrm{~min}$ at 13,000 rotations/min. Upon completion of centrifuging, the supernatant was decanted and then drained with the use of a paper towel. RNA residue was rinsed in $1000 \mu$ l of $70 \%$ ethanol and centrifuged for $10 \mathrm{~min}$ at $4^{\circ} \mathrm{C}$ at 10,000 rotations/min. The procedure was completed with drying off RNA extracts at ambient temperature. The extracts were evaluated in terms of their quality with the application of qualitative electrophoresis and in terms of their quantity by means of spectrophotometry with the use of GeneQuant II (Pharmacia Biotech).

\section{Quantitative real-time reverse transcription} polymerase chain reaction assay (RTqPCR)

The RT-qPCR reaction was conducted with the use of Opticon ${ }^{\mathrm{TM}}$ DNA Engine Sequence Detector (MJ Research Inc., Watertown, MA, USA) with the use of SYBR Green Quantitect RT-PCR Kit (Qiagen, Valencia, CA, USA). Thermal conditions for the conducted reaction were as follows: reverse transcription (RT) reaction was conducted at a temperature of $50^{\circ} \mathrm{C}$ for $30 \mathrm{~min}$, amplification was conducted at the following temperatures: $95^{\circ} \mathrm{C}$ for $15 \mathrm{~min}$; 42 two-stage cycles: $94^{\circ} \mathrm{C}$ for $30 \mathrm{~s}$ and $60^{\circ} \mathrm{C}$ for $60 \mathrm{~s}$ and final extension: $72^{\circ} \mathrm{C}$ for $30 \mathrm{~s}$. Sequences of starters used in the reaction are given in Table 1 . The analysis was performed with the use of $\beta$-actin (ACTB) and GAPDH as endogenic controls.

Transcription activity was presented as the number of mRNA copies of a specific gene, converted into $1 \mu \mathrm{g}$ of total RNA.

\section{Ethics}

Consent of the Bioethics Commission of Medical University of Silesia in Katowice/Poland no. KNW/0022/ KB1/59/I/13/14.

\section{Statistical analysis}

The statistical analysis of the results of the expression change in examined genes was performed with the

Table 1. Starter sequences used in the RTqPCR reaction

\begin{tabular}{lc}
\hline Gene & Oligonucleotide sequence \\
\hline TGF- $\beta 1$ & $\begin{array}{c}\text { Forward: 5'TGAACCGGCCTTTCCTGCTTCTCATG3' } \\
\text { Reverse: 5'GCGGAAGTCAATGTACAGCTGCCGC3' }\end{array}$ \\
\hline TGF- $\beta 2$ & $\begin{array}{c}\text { Forward: 5'TACTACGCCAAGGAGGTTTACAAA3' } \\
\text { Reverse: 5'TTGTTCAGGCACTCTGGCTTT3' }\end{array}$ \\
\hline TGF- $\beta 3$ & $\begin{array}{c}\text { Forward: 5'CTGGATTGTGGTTCCATGCA3' } \\
\text { Reverse: 5'TCCCCGAATGCCTCACAT3' }\end{array}$ \\
\hline TGF- $\beta R I$ & $\begin{array}{c}\text { Forward: 5'-ACTGGCAGCTGTCATTGCTGGACCAG-3' } \\
\text { Reverse: 5'-CTGAGCCAGAACCTGACGTTGTCATATCA-3' }\end{array}$ \\
\hline TGF- $\beta R I I$ & $\begin{array}{c}\text { Forward: 5'-GGCTCAACCACCAGGGCATCCAGAT-3' } \\
\text { Reverse: 5'-CTCCCCGAGAGCCTGTCCAGATGCT-3' }\end{array}$ \\
\hline TGF- $\beta R I I I$ & $\begin{array}{c}\text { Forward: 5'-ACCGTGATGGGCATTGCGTTTGCA-3' } \\
\text { Reverse: 5'-GTGCTCTGCGTGCTGCCGATGCTGT-3' }\end{array}$ \\
\hline ACTB & $\begin{array}{c}\text { Forward: 5'-TCACCCACACTGTGCCCATCTACGA-3' } \\
\text { Reverse: 5'-CaGCGGaacCGctcattGCCaatGG-3' }\end{array}$ \\
\hline GAPDH & $\begin{array}{c}\text { Forward: 5'-GAAGGTGAAGGTCGGAGTC-3' } \\
\text { Reverse: 5'-GAAGATGGTGATGGGATTC-3' }\end{array}$ \\
\hline
\end{tabular}


Table 2. Change in TGF $\beta 1-3$ and TGF $/-1 /$ transcription activity during 84 days of treatment

\begin{tabular}{|c|c|c|c|c|c|}
\hline Name of the group & mRNA & $\begin{array}{l}\text { Median (the number } \\
\text { of mRNA copies of } \\
\text { gene/1 } \mu \text { g total RNA) }\end{array}$ & $\begin{array}{l}\text { Lower quartile (the } \\
\text { number of mRNA copies } \\
\text { of gene/ } 1 \mu \mathrm{g} \text { total RNA) }\end{array}$ & $\begin{array}{c}\text { Upper quartile (the number } \\
\text { of mRNA copies of gene/ } \\
1 \mu \text { total RNA) }\end{array}$ & $\begin{array}{c}\text { ANOVA } \\
\text { Friedman test } \\
p<0.05\end{array}$ \\
\hline Day 0 of treatment & \multirow[t]{3}{*}{$T G F-\beta 1$} & 497000 & 190000 & 873000 & \multirow[t]{3}{*}{$<0.001$} \\
\hline Day 42 of treatment & & 394000 & 74500 & 3060000 & \\
\hline Day 84 of treatment & & 466500 & 152000 & 2640000 & \\
\hline Day 0 of treatment & \multirow[t]{3}{*}{$T G F-\beta 2$} & 6790 & 1160 & 46800 & \multirow[t]{3}{*}{0.55} \\
\hline Day 42 of treatment & & 2360 & 915 & 72200 & \\
\hline Day 84 of treatment & & 3615 & 672 & 6520 & \\
\hline Day 0 of treatment & \multirow[t]{3}{*}{$T G F-\beta 3$} & 227500 & 85650 & 738500 & \multirow[t]{3}{*}{$<0.001$} \\
\hline Day 42 of treatment & & 1030000 & 260000 & 1770000 & \\
\hline Day 84 of treatment & & 367000 & 52000 & 879000 & \\
\hline Day 0 of treatment & \multirow[t]{3}{*}{$T G F-\beta R I$} & 73400 & 37200 & 444000 & \multirow[t]{3}{*}{$<0.001$} \\
\hline Day 42 of treatment & & 144500 & 94400 & 794000 & \\
\hline Day 84 of treatment & & 82050 & 15700 & 904500 & \\
\hline Day 0 of treatment & \multirow[t]{3}{*}{$T G F-\beta R I I$} & 425000 & 75300 & 1010000 & \multirow[t]{3}{*}{0.00001} \\
\hline Day 42 of treatment & & 360500 & 50700 & 996000 & \\
\hline Day 84 of treatment & & 247500 & 77400 & 944500 & \\
\hline Day 0 of treatment & \multirow{3}{*}{$\begin{array}{l}\text { TGF- } \\
\beta R I I I\end{array}$} & 286500 & 111000 & 749000 & \multirow[t]{3}{*}{$<0.001$} \\
\hline Day 42 of treatment & & 194000 & 100000 & 930000 & \\
\hline Day 84 of treatment & & 198000 & 123000 & 474000 & \\
\hline
\end{tabular}

use of a licensed version of Statistica $12 \mathrm{PL}$ (StatSoft, Tulsa, Oklahoma, USA), assuming the statistical gravity factor of $p<0.05$. The analysis was performed with the use of non-parametric methods; the median, and upper and lower quartiles were used to describe the number of mRNA copies of gene/1 $\mu \mathrm{g}$ total RNA (Table 2). The Kruskal-Wallis test was conducted, and in case of statistically significant differences between expressions of the individual TGF- $\beta$ isoform and its TGF- $\beta$ Rs receptors at a given moment - a post-hoc multi-comparison test. The ANOVA Friedman test and post-hoc ANOVA Friedman were also performed in order to show the statistical significance of a given TGF- $\beta$ isoform and its receptors on day 0,42 , and 84 of observation of the efficacy of CSA therapy.

\section{Results}

With regard to TGF- $\beta 1$, when compared with the observation commencement, we observed that on day 42 there was a decrease in the expression and on day 84 of exposure to the medicine, there occurred another increase in the number of transcripts of this gene. A similar trend is observed in case of TGF- $\beta 2$. TGF- $\beta 3$ transcription activity increases after 42 days of treatment, however further prolongation of medicine administration decreases the expression with a likely tendency for the expression to reach the baseline level.
When analysing the expression of TGF- $\beta R /-I / I$ receptors, it may be observed that the expressions of TGF- $\beta R / I$ and TGF- $\beta R / / I$ are continuously lower. Whereas, as far as $T G F-\beta R /$ is concerned, we observe overexpression on day 42 , when compared with the control sample (day 0), and twice longer period of CSA administration leads to a decreased transcription activity, the expression of which seems to be comparable to that of the control sample.

In order to determine statistically important differences of expressions of various TGF- $\beta$ s isoform and its $T G F-\beta R$ s receptors, the Kruskal-Wallis test was conducted and, in case of statistically important differences a post-hoc multi-comparison test, too. Important differences of transcript quantities were determined between TGF- $\beta 1$ and TGF- $\beta 2(p<0.001)$ and between TGF- $\beta 2$ and TGF- $\beta 3$ ( $p<0.001)$ on each stage of the pharmacotherapy period (day 0, day 42, day 84). In case of receptors, there are no statistically significant differences of expressions at a given moment of therapy (Figure 1).

When analysing variances in the expression profiles of the specific isoforms between the individual days of therapy, the ANOVA Friedman test was performed and, in case of statistically important differences - post-hoc ANOVA Friedman, too.

In case of TGF- $\beta 1$ ( $p<0.001)$, statistically significant differences of expressions were determined between the following periods: day 0 and day 42 , day 0 and day 84 , 


\section{A}

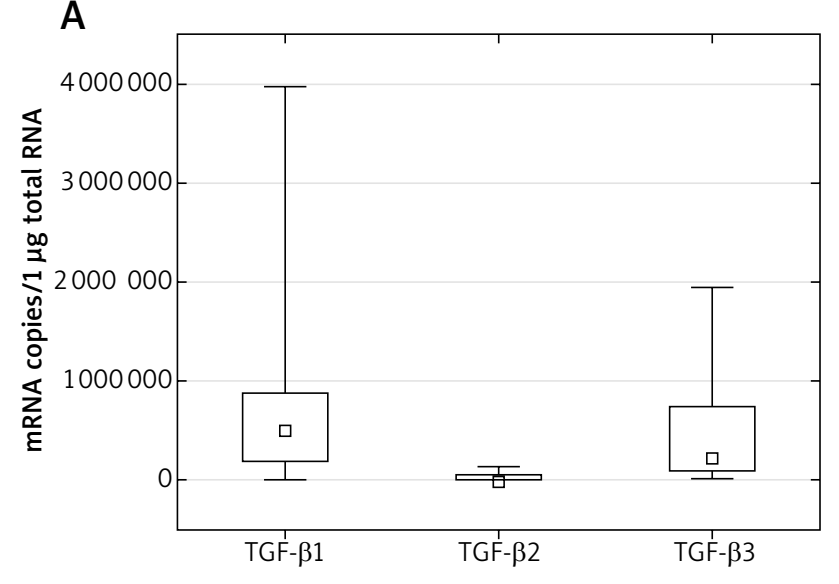

$\square$ Median

$\square_{25-75 \%}$

I Min.-max.
B

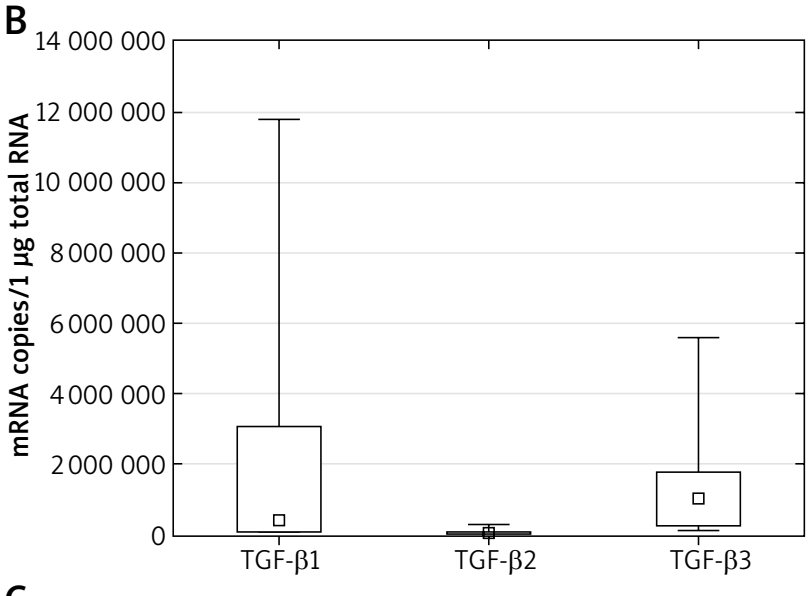

C

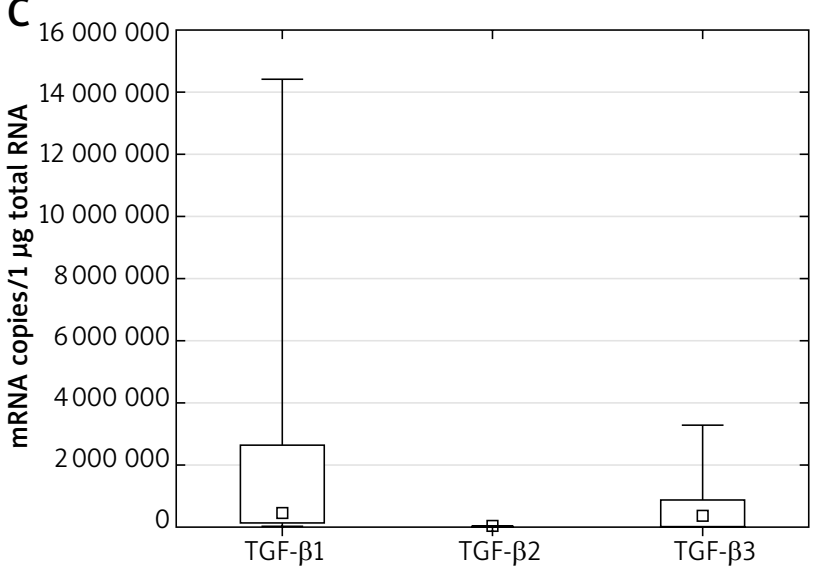

A

Figure 1. TGF- $\beta 1-3$ expression profile on the day of therapy commencement day 0 (A), on day 42 (B), on day 84 (C)

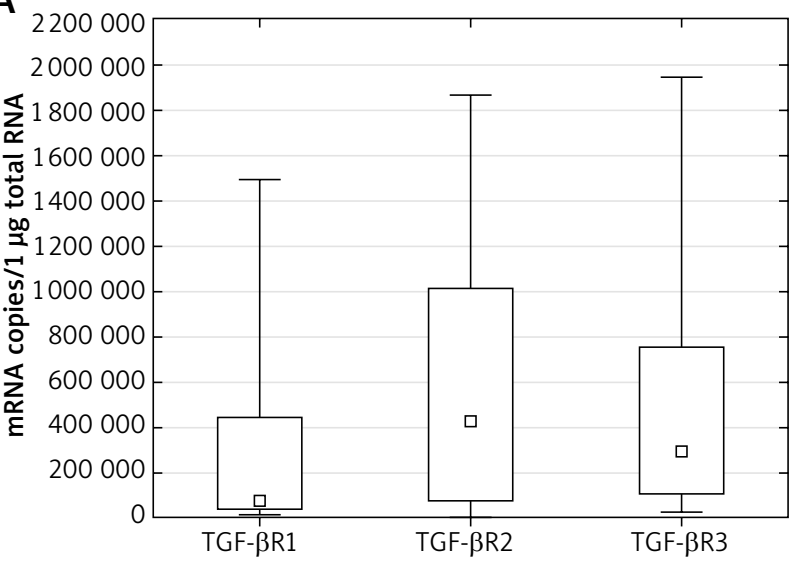

$\square$ Median

$\square 25-75 \%$

IMin.-max.

Figure 2. TGF- $\beta$ RI-III expression profile on the day of therapy commencement day 0 (A), on day 42 (B), on day 84 (C)
B
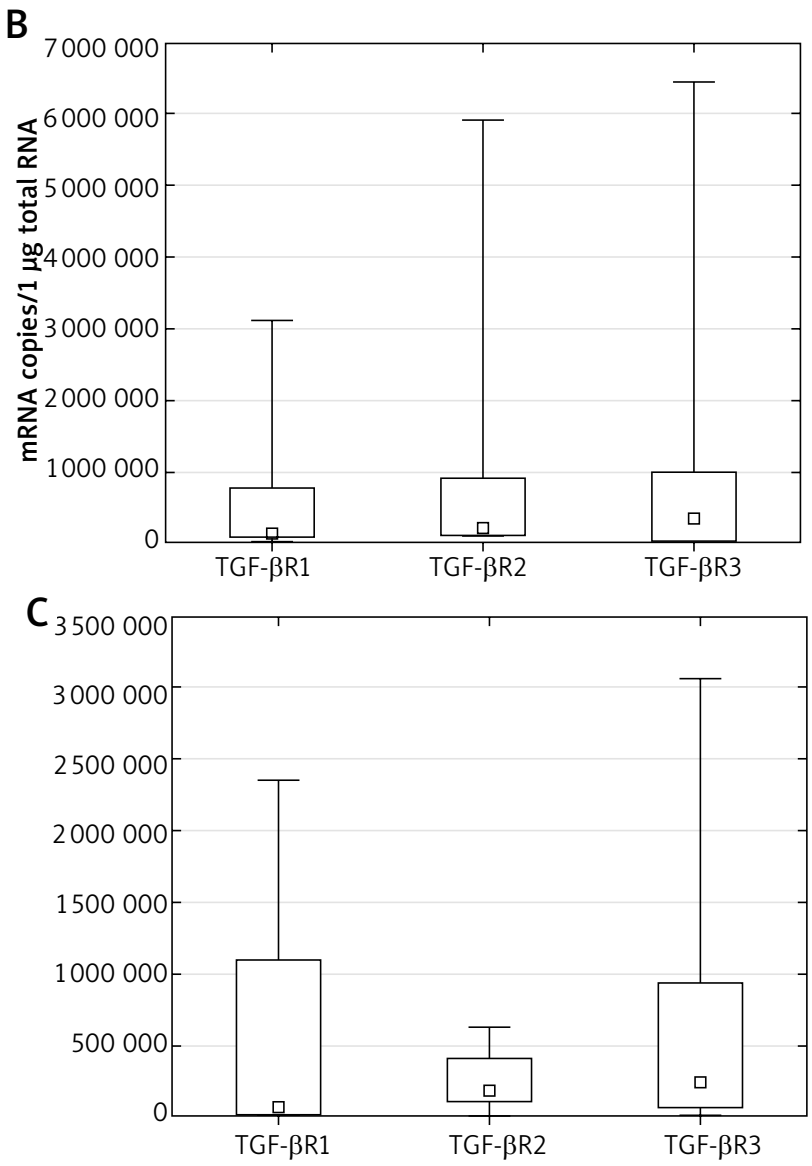
and day 42 and day 84 . In case of TGF- $\beta 2$, the statistical analysis did not show any statistically significant differences in the expressions of this gene $(p=0.055)$. Statistically significant differences were determined in case of TGF- $\beta 3$ ( $p<0.001)$ between the following: day 0 and day 42 , and day 42 and day 84 . ANOVA Friedman analysis showed that variances in the TGF- $\beta R /$ and TGF- $\beta R / I$ expressions are statistically significant $(p<0.001)$ and occur between day 0 and day 42, and day 42 and day 84. Also in case of TGF- $\beta R I I I$, the ANOVA Friedman variance analysis showed that differences in the expression of this gene are statistically significant $(p<0.001)$ and they may be observed between the following periods: day 0 to day 42 and day 0 to day 84 (Figure 2).

\section{Discussion}

Psoriasis is a chronic, inflammatory skin disorder with the prevalence from $0.9 \%$ to $8.5 \%$ [26]. Complex pathophysiology of psoriasis includes cooperation between keratinocytes of epidermis, T lymphocytes and endothelial cells. With regard to ethiopathogenesis, it is classified as the inflammatory disease through a strong and inseparable relationship with the immunological system, which translates into an increased concentration of pro-inflammatory cytokines [27-36].

Recently recommended pharmacotherapy includes: CSA, acitretin (second-generation synthetic retinoid), and biological medicines are used more and more often [28, 37, 38].

Keratinocyte proliferation and their incorrect differentiation, as well as focal infiltrations consisting of neutrophils and lymphocytes within the epidermis and dermis lead to release of a series of cytokines, which play a crucial role in the pathogenesis of psoriasis. That is why, current methods of psoriasis treatment are aimed to suppress inflammatory response through immunomodulation, affecting $T$ lymphocytes, dendritic cells and keratinocytes. Cyclosporin A belongs to such medicines. It has also been applied to treat autoimmunologic diseases, such as atopic dermatitis and rheumatoid arthritis [39-41].

Cyclosporin A is used as one of the first-line drugs in the treatment of moderate and severe forms of psoriasis, defined through presence of the specific indexes: BSA $>10$, PASI > 10 and DLQI > 10 according to the European Consensus of Experts. It is a therapeutic drug with immunomodulatory properties through suppressing inflammatory cells. Cyclosporin A inhibits keratinocyte proliferation, as well as expression of ICAM-1 endothelial cell adhesion and E-selectin.

In their study, Abe et al. proved that CsA affects not only keratinocytes, but also skin fibroblasts, and the effects of its action depend on interleukin 6 (IL-6), the determinant of which is rebuilding of ECM and effect on immunocompetent cells [42]. Janikowska et al. also conducted trials concerning signalling paths where CSA plays a key role. The objective of the experiment was to evaluate the effect of CSA on the proliferation of healthy human skin fibroblasts through examination of variances in expression profiles of genes involved in the cellular cycle regulation and transcription processes [43].

Analogous trials with regard to CSA and its effect on psoriasis were conducted by Elango and Thirupathi, but with the use of methotrexate (MTX), which is also an immunosuppressive medicine. The aim of the trial was to find the pharmacological effect of MTX on the incorrect proliferation of keratinocytes and disturbed inflammatory response induced by uncontrollable expression of immunologic mediators. Results achieved by the said research team show a considerably reduced expression of mRNA gene encoding TNF- $\alpha$ and IFN-g and an increased expression of TGF- $\beta 1$ upon completion of MTX therapy (after 6 and 12 weeks) when compared with the period before exposure of psoriatic patients to methotrexate [44]. They show the efficacy and legitimacy of immunosuppressive therapy in psoriatic patients.

Transforming growth factor $\beta$ is one of the most known pleiotropic and multi-purpose peptides, generated by various types of cells, taking part in many metabolic processes, including cellular proliferation, their differentiation, apoptosis and is generated in response to ongoing inflammation $[45,46]$. Transforming growth factor $\beta$ is a natural and strong growth inhibitor of various types of cells, including epithelial cells, endothelial cells and hematopoietic cells $[47,48]$. Deregulation in the secretion and functions performed by TGF- $\beta$ was documented in various skin diseases, including psoriasis, wound healing disorders, formation of hypertrophic scars and skin cancer. Moreover, this peptide is perceived as an efficient inhibitor of keratinocyte proliferation in psoriasis [45].

Transforming growth factor $\beta 1$, which is a strong inhibitor of cellular proliferation, is synthesised as a precursor, separated inside cells in the form of inactive complex covering mature TGF- $\beta 1$, non-covalently bound with a part of peptide (LAP) releasing directly from extracellular matrix $[49,50]$. Extracellular activation of TGF- $\beta 1$ occurs after its release from the complex. TGF- $\beta$ then transmits the signal inside the cell through Smad 2 and Smad3 phosphorylation. Following phosphorylation of protein and Smad2, they form a complex with Smad4, gather inside the nucleus and act as transcription agents. This cascade of events changes the gene expression in keratinocytes, which inhibits proliferation, increases diversification and susceptibility to apoptosis [51, 52].

On the basis of results of their research, Liu and Feng underline that CD109 protein may act synergistically with Smad7 protein, thus reducing TGF- $\beta$ RI expression and lead to TGF- $\beta$ signalling completion in psoriasis [45]. Zhang and Meng confirmed their hypothesis stating that TGF- $\beta 1$ plays a role in the development of psoriatic pathological lesions by means of the mechanism triggered by 
Smad3 inhibitor. They conducted their experiment with the use of a transgenic $\mathrm{K} 5$ mouse model. Local treatment with the use of Smad3 inhibitor blocked TGF- $\beta$ signalling, which in turn contributed to reduced advancement of psoriasis, reduced infiltration of intumescence from lymphocytes $\mathrm{T} \mathrm{CD}^{+}$and macrophages and halting the fibrotic process in the skin. It involved considerably reduced quantities of TGF- $\beta 1$ and IL-6, IL-23 and IL-17A. Managing TGF- $\beta /$ Smad3 signalling with the use of Smad3 inhibitor may constitute a new and efficient option in psoriasis therapy [52-54].

In this paper, an attempt was made to assess changes in mRNA transcription activity of genes encoding isoforms of the $\beta$ transforming growth factor: TGF- $\beta 1$, TGF- $\beta 2$, TGF- $\beta 3$ and its receptors: TGF- $\beta$ R1, TGF- $\beta$ R 2 and TGF- $\beta$ R3 in patients with moderate and severe forms of psoriasis. They were examined on the basis of patients' whole blood, taken in accordance with the assumed standards. Material for transcriptome was taken thrice: before treatment (day 0), on day 42 and day 84 of the therapy.

Results of the research conducted at the transcriptome level aimed at deepening the knowledge on the disease ethiopathogenesis, basing on molecular mechanisms involving the development of inflammation present during the dermatosis and looking for supplementary diagnostic markers, as well as new therapeutic strategies.

In order to determine the therapeutic potential of CSA in the treatment of psoriasis and the possibility of using TGF- $\beta$ s and its TGF- $\beta$ R receptors as control markers of the said disease, interpretation of the profile variances in the genes encoding TGF $\beta 1-3$ and its TGF $\beta$ RI-III receptors during the 84-day long therapy was also performed. When analysing the achieved results of expression profile variances of examined mRNA of genes, coupled with the clinical observation of patients, it is ascertained that the best molecular diagnostic marker is TGF- $\beta 1$, when compared with the other TGF $\beta$ isoforms and their receptors, which are characterised by considerable heterogeneity of expression during the 84-day long observation of the efficacy of the CSA therapy. It could also be presumed so, taking into account the fact that an increased TGF- $\beta 1$ expression correlated with the improved local condition of the skin in the course of psoriasis, which was observed during regular check-ups of the patients.

\section{Conclusions}

Gene expression variances and signal transduction through a pleiotropic cytokine from the TGF- $\beta$ family contributes to better ethiopathogenesis of psoriasis. However, further trials and analyses would be advisable at the level of transcriptome and proteome. Results of this study also indicate the efficacy of pharmacotherapy with the use of CSA and the legitimacy of molecular tests, which make it possible to analyse mechanisms underlying the inflammatory process, as well as underline the possibility of using TGF- $\beta 1$ as a supplementary diagnostic marker in psoriasis. Determination of transcription activity variances of genes involving a given pathological process or cellular response to a given medicine is justified because molecular changes precede phenotypic changes. Consequently, introduction of determination of the mRNA level of the TGF- $\beta 1$ isoform in the diagnostics and treatment would make it possible to detect psoriatic patients' sensitivity to CSA, enabling one to change the therapeutic strategy sufficiently early. The positive result would be the increased safety of the therapy and a decreased number of incidences and intensity of disease exacerbation due to the possible early loss of sensitivity to the drug, which does not reveal itself phenotypically.

\section{Acknowledgments}

This research was financed by the Medical University of Silesia in Katowice/Poland on the basis of decision no. KNW-1-029/N/6/O.

\section{Conflict of interest}

The authors declare no conflict of interest.

\section{References}

1. Tsoi LC, Stuart PE, Tian C, et al. Large scale meta-analysis characterizes genetic architecture for common psoriasis associated variants. Nat Commun 2017; 24: 15382.

2. Wang H, Peters T, Sindrilaru A, et al. TGF-beta-dependent suppressive function of Tregs requires wild-type levels of CD18 in a mouse model of psoriasis. J Clin Invest 2008; 118: 2629-39.

3. Szepietowski J, Adamski Z, Chodorowska G, et al. Leczenie łuszczycy - rekomendacje ekspertów Polskiego Towarzystwa Dermatologicznego. Część Il: łuszczyca umiarkowana do ciężkiej. Przegl Dermatol 2014; 101: 455-72.

4. Miller IM, Ellervik C, Yazdanyar S, Jemec GB. Meta-analysis of psoriasis, cardiovascular disease, and associated risk factors. J Am Acad Dermatol 2013; 69: 1014-24.

5. Praveenkumar U, Ganguly S, Ray L, et al. Prevalence of metabolic syndrome in psoriasis patients and its relation to disease duration: a hospital based case-control study. J Clin Diagn Res 2016; 10: WC01-5.

6. Machado-Pinto J, Diniz Mdos S, Bavoso NC. Psoriasis: new comorbidities. An Bras Dermatol 2016; 91: 8-14.

7. Furue M, Kadono T. Psoriasis: behind the scenes. J Dermatol 2016; 43: 4-8.

8. Itani S, Arabi A, Harb D, et al. High prevalence of metabolic syndrome in patients with psoriasis in Lebanon: a prospective study. Int I Dermatol 2016; 55: 390-5.

9. Grabarek B, Bednarczyk M, Mazurek U. The characterization of tumor necrosis factor alpha (TNF- $\alpha$ ), its role in cancerogenesis and cardiovascular system diseases and possibilities of using this cytokine as a molecular marker. Acta Univ Lodz Folia Biol Oecol 2017; 13: 1-8. 
10. Singh S, Young P, Armstrong AW. An update of psoriasis and metabolic syndrome: a meta-analysis of observational studies PLos One 2017; 12: e0181039.

11. Ryan C, Kirby B. Psoriasis is a systemic disease with multiple cardiovascular and metabolic comorbidities. Dermatol Clin 2015; 33: 41-55.

12. Gelfand JM. Psoriasis, type 2 diabetes mellitus, and obesity: weighing the evidence. JAMA Dermatol 2016; 152: 753-4.

13. Shenoy C, Shenoy MM, Rao GK. Dyslipidemia in dermatological disorders. N Am J Med Sci 2015; 7: 421-8.

14. Salunke AS, Nagargoje MV, Belgaumkar VA. Association of metabolic syndrome in chronic plaque psoriasis patients and their correlation with disease severity, duration and age: a case control study from Western Maharashtra. J Clin Diag Res 2017; 11: 6-10.

15. Gisondi P, Fostini AC, Fossà I, et al. Psoriasis and the metabolic syndrome. Clin Dermatol 2018; 36: 21-8.

16. Lønnberg AS, Skov L, Skytthe A, et al. Association of psoriasis with the risk for type 2 diabetes mellitus and obesity. JAMA Dermatol 2016; 152: 761-7.

17. Guo P, Luo Y, Mai G, et al. Gene expression profile based classification models of psoriasis. Genomics 2014; 103: 48-55.

18. Meki AR, Al-Shobaili H. Serum vascular endothelial growth factor, transforming growth factor beta1, and nitric oxide levels in patients with psoriasis vulgaris: their correlation to disease severity. J Clin Lab Anal 2014; 28: 496-501.

19. Kajdaniuk D, Marek B, Borgiel-Marek H, et al. Transforming growth factor beta1 (TGF $\beta 1$ ) in physiology and pathology. Endokrynol Pol 2013; 64: 384-96.

20. Schafer PH, Truzzi F, Parton A, et al. Phosphodiesterase 4 in inflammatory diseases: effects of apremilast in psoriatic blood and in dermal myofibroblasts through the PDE4/ CD271 complex. Cell Signal 2016; 28: 753-63.

21. Zhang Y, Meng XM, Huang XR, et al. Transforming growth factor-beta1 mediates psoriasis-like lesions via a Smad3dependent mechanism in mice. Clin Exp Pharmacol Physiol 2014; 41: 921-32.

22. Michalak-Stoma A, Bartosińska J, Chodorowska G, et al. Serum levels of selected Th17 and Th22 cytokines in psoriatic patients. Dis Markers 2013; 35: 625-31.

23. Dehesa L, Abuchar A, Nuno-Gonzalez A, et al. The use of cyclosporine in dermatology. J Drugs Dermatol 2012; 11: 979-87.

24. Vassantachart JM, Sharon JE. Cyclosporine in the treatment of psoriasis. J Dermatol Nurses' Assoc 2017; 9: 98-101.

25. Armstrong AW, Aldredge L, Yamauchi PS. Managing patients with psoriasis in the busy clinic: practical tips for health care practitioners. J Cutan Med Surg 2016; 20: 196-206.

26. Molina-Leyva A, Almodovar-Real A, Carlos-Ruiz C, et al. Distribution pattern of psoriasis, anxiety and depression as possible causes of sexual dysfunction in patients with moderate to severe psoriasis. An Bras Dermatol 2015; 90: 338-45.

27. Wcisto-Dziadecka D, Grabarek B, Zmarzły N. Influence of adalimumab on the expression profile of genes associated with histaminergic system in the skin fibroblasts in vitro. BioMed Res 2018; 2018: 1582173.

28. Wu WZ, Zhang FR. Glycyrrhizin combined with acitretin improve clinical symptom of psoriasis via reducing Th17 cell differentiation and related serum cytokine concentrations. Int J Clin Exp Med 2015; 9: 16266-72.

29. Peng C, Zhang S, Lei L, et al. Epidermal CD147 expression plays a key role in IL-22-induced psoriasis dermatitis. Sci Rep 2017; 7: 44172.

30. Wcisło-Dziadecka D, Zbiciak M, Wcisło-Brzezińska L, et al. Anti-cytokine therapy for psoriasis - not only TNF blockers.
Overview of reports on the effectiveness of therapy with IL12/IL23 and T and B lymphocyte inhibitors. Post Hig Med Dosw 2016; 70: 1198-205.

31. Gubán B, Vas K, Balog Z, et al. Abnormal regulation of fibronectin production by fibroblasts in psoriasis. $\mathrm{Br} J$ Dermatol 2016; 174: 533-41.

32. Arora N, Shah K, Pandey-Rai S. Inhibition of imiquimodinduced psoriasis-like dermatitis in mice by herbal extracts from some Indian medicinal plants. Protoplasma 2016; 253: 503-15.

33. Feng AP, He YM, Liu XX, et al. Expression of USP15, TbetaR-I and Smad7 in psoriasis. J Huazhong Univ Sci Technolog Med Sci 2014; 34: 415-9.

34. Michalak-Stoma A, Pietrzak A, Chodorowska G, et al. Cytokine network in psoriasis revisited. Eur Cytokine Netw 2011; 22: $160-8$

35. Puig L. The role of IL-23 in the treatment of psoriasis. Expert Rev Clin Immunol 2017; 13: 525-34.

36. Pietrzak A, Zalewska A, Chodorowska G, et al. Genes and structure of selected cytokines involved in pathogenesis of psoriasis. Folia Histochem Cytobiol 2008; 46: 11-21.

37. Kallimanis PG, Xenos K, Markantonis SL, et al. Serum levels of transforming growth factor-beta1 in patients with mild psoriasis vulgaris and effect of treatment with biological drugs. Clin Exp Dermatol 2009; 34: 582-6.

38. Khawaja AR, Bokhari SM, Tariq R, et al. Disease severity, quality of life, and psychiatric morbidity in patients with psoriasis with reference to sociodemographic, lifestyle, and clinical variables: a prospective, cross-sectional study from Lahore, Pakistan. Prim Care Companion CNS Disord 2015; 17(3). doi: 10.4088/PCC.14m01629. eCollection 2015.

39. Ikonomidis I, Varoudi M, Makavos G. Greater improvement of coronary artery function, left ventricular deformation and twisting by treatment with IL-17A antagonist compared to cyclosporine in psoriasis. Eur Heart J 2017; 38: doi. org/10.1093/eurheartj/ehx504.P3340.

40. Choi CW, Kim BR, Ohn J, et al. The advantage of cyclosporine $A$ and metothrexate retational therapy in long-term systemic treatment for chronic plaque psoriasis in a real world practice. Ann Dermatol 2017; 29: 55-60.

41. Bălaşa R, Maier S, Voidăzan S, et al. Assessment of IL-17A, IL-10 and TGF-beta1 serum titers in RRMS patients treated with Avonex, possible biomarkers for treatment response. CNS Neurol Disord Drug Targets 2016; 15 [Epub ahead of print].

42. Abe M, Yokoyama Y, Syuto T, et al. Interleukin-6 counteracts effects of cyclosporin A on extracellular matrix metabolism by human dermal fibroblasts. Cell Tissue Res 2008; 333: 281-8.

43. Janikowska G, Janikowsk T, Pyka A, et al. Cyclosporin A affects the proliferation process in normal human dermal fibroblasts. Acta Pol Pharm 2016; 73: 55-63.

44. Elango T, Thirupathi A, Subramanian S, et al. Methotrexate normalized keratinocyte activation cycle by overturning abnormal keratins as well as deregulated inflammatory mediators in psoriatic patients. Clin Chim Acta 2015; 451: 329-37.

45. Liu XX, Feng AP, He YM, et al. Association of down-regulation of CD109 expression with up-expression of Smad7 in pathogenesis of psoriasis. J Huazhong Univ Sci Technolog Med Sci 2016; 36: 132-6.

46. Micali G, Lacarrubba F, Musumeci ML, et al. Cutaneous vascular patterns in psoriasis. Int I Dermatol 2010; 49: 249-56.

47. Xiaoging G, Hutcheon AEK, Tran JA, et al. TGF-beta-target genes are differentially regulated in cornela epithelial cells 
and fibroblasts. New Front Opathanol 2017; 3: doi: 10.15761/ NFO.1000151.

48. Liu R, Wang Y, Zhao X, et al. Lymphocyte inhibition is compromised in mesenchymal stem cells from psoriatic skin. Eur J Dermatol 2014; 24: 560-7.

49. Chruścik A, Gopalan V, Lam AK. The clinical and biological roles of transforming growth factor beta in colon cancer stem cells: a systemic review. Eur J Cell Biol 2018; 97: 15-22.

50. Biernacka A, Dobaczewski M, Frangogiannis NG. TGF-beta signaling in fibrosis. Growth Factors 2011; 29: 196-202.

51. Leivo T, Leivo I, Kariniemi AL, et al. Down-regulation of transforming growth factor-beta receptors I and II is seen in lesional but not non-lesional psoriatic epidermis. Br J Dermatol 1998; 138: 57-62.

52. Man XY, Chen XB, Li W, et al. Analysis of epithelial-mesenchymal transition markers in psoriatic epidermal keratinocytes. Open Biol 2015; 5 pii: 150032 doi: 10.1098/ rsob.150032.

53. Jiang M, Sun Z, Dang E. TGF $\beta / S M A D / m i c r o R N A-486-3 p$ signaling axis mediates keratin 17 expression and keratinocyte hyperproliferation in psoriasis. J Investig Dermatol Symp Proc 2017; 137: 2177-86.

54. Napolitano M, Balato N, Ayala F, et al. Psoriasis in elderly and non elderly population: clinical and molecular features. G Ital Dermatol Venereol 2016; 151: 587-95. 